\title{
The Analysis of Deficiency in College-student English Oral Expression Ability and Strategies for Breaking Barriers
}

\author{
GAO Jin-chi, JIN Ming-hao (Corresponding Author) \\ Department of English, Yanbian University, Yanji, Jilin Province, China
}

\begin{abstract}
Referring to the questionnaire surveys and literature materials, this paper describes the current situation of college students' English oral expression ability, the reasons for lack of such ability and possible solutions. This research used a questionnaire survey to collect data from 146 college students from different grades, majors, universities and areas. The result shows that the deficiency in college students' English oral expression ability can be explained on two levels, spiritual level and oral level. Spiritual level shows that college students don't always have thoughts while others are communicating with them in English; oral level includes two aspects, one is that they always have no idea of how to express their thoughts well and the other is that they fail to always express themselves clearly and exactly. It is suggested that a good language environment is necessary for students to practice English pronunciation, understand culture from English speaking countries, and enhance listening skill to overcome language anxiety in communication.
\end{abstract}

Keywords: college students, English oral expression ability, language environment, language anxiety

\section{Introduction}

With the further development of English teaching reform in recent years, there is no denying that college students' English proficiency has been on the rise overall. However, according to Zheng's (2010) analysis of the current situation, compared with the five basic language skills, listening, speaking, reading, writing and interpreting, college students' English oral expression ability is generally low. What's worse, there are over $70 \%$ college students in the state of "Mute English" according to Sogou Baike.

The Ministry of Education enacted "College English Course Teaching Requirement” in January 2014, which said "The purpose on college-student English teaching is to cultivate students' comprehensive proficiency in applying English, especially listening and speaking ability.” This requirement identifies and defines three different levels of English oral expression ability for college students. They are:

1. The general requirement is that college students "are capable of communicating in English, making a brief presentation about their familiar topics after preparation."

2. The intermediate requirement is that college students "are capable of making a fairly fluent conversation on some general topics in English, basically expressing personal suggestions, reasons and describing events with clear expressions and correct tongue."

3. The higher requirement is that college students "are capable of making a fluent and correct conversation 
or discussion on some general or professional topics.”

Zhao (2013) mentioned that the main purpose of learning English is to communicate. Nevertheless, Chinese English course teaching is flawed because courses emphasize grammar, reading and writing abilities over English communication and training. The study also proposed that the current situation of college students' English oral expression ability is not optimistic.

This paper will describe why college students are lacking of English oral expression ability and suggest some solutions to address those relevant problems.

\section{Theoretical Background}

\section{Definition of English Oral Expression Ability}

Oral expression is the base of other language activities. According to Guo (2004), teaching psychology research shows that in foreign language activities, oral expression ability not only includes the factor of foreign language oral expression skills, but the factor of foreign language oral expression ability. The former shows actual expressive status of oral expression, while the latter represents potential restriction on the former.

\section{Empirical Studies on Deficiency in English Oral Expression Ability}

Schavan (2003) pointed out that children under six years old can learn any kind of language taught at the same time. But once over that age, it's hard for them to take in any new foreign language thoroughly, suggesting that mother tongue and language environment may affect English oral expression ability.

Guo (2004) divided three stages of the development of college-student English oral expression ability: The first is comfortless expression stage of absorption and digestion; The second is independent expression stage of processing and combination; The third is free expression stage of extracting and creation.

Zheng (2010) identified fundamental hurdles that restrict college students' long-term improvement in English oral expression ability, including the lack of genuine language environment, neglecting English oral expression in middle and high school teaching, and college students not realizing the importance of English oral expression ability.

Zhu (2011) not only mentioned the lack of real language environment and standard of English teaching, but also suggested cultural factors, character factors and resistance to language anxiety.

Nevertheless, none of them scanned widely the development of students' deficiency in English oral expression ability, so this paper will analyze reasons for this deficiency and suggest some possible solutions.

\section{Research Design}

\section{Research Questions}

There are three research questions in this paper. They are:

1. What is the current situation of college-student English oral expression ability?

2. What are the causes of deficiency in college-student English oral expression ability?

3. What are the possible strategies to improve the deficiency of college-student English oral expression ability?

\section{Data Collection and Analysis}

A questionnaire survey with 21 questions written in Chinese was designed and shared. 150 responses were received from random college students on the Internet, shared the questionnaire link to Wechat in SOJUMP. 
Among them, 146 responses are valid in statistics.

Participants. The participants in this research were 146 college students from different grades, majors, universities or colleges and areas, ensuring that collected data and analyzed results are impartial, objective and representative. Among them, 45.95\% participants are from English major and 54.05\% from non-English major. And survey covers 25 diverse four-year universities or colleges in 16 cities around China and overseas.

Instrument. A questionnaire was designed to collect data, which contains two sections, questions examining the current situation of college students' English oral expression ability and possible causes of deficiency in college students’ English oral expression ability.

\section{Result and Discussion}

The current status will be analyzed from two aspects, students' self-evaluation of English oral expression ability and three kinds of reactions when they communicate with others in English.

\section{Current Status}

According to the questionnaire survey, 63.01\% participants have learned English for over 10 years; however, only $5.48 \%$ of them strongly agreed that their English oral expression ability is good enough. Meanwhile, about half of them (50.68\%) were still unsure about their English oral expression level. Considering the long period of learning English and the judgments on their English oral expression ability, current status of college-students' English oral expression ability is not satisfactory.

Self-evaluation. Self-evaluation is a good method for college students to see through things, especially something that's hard to recognize. The next four questions show participants' self-evaluation of their English oral expression ability (shown in Table 1 and Table 2).

Table 1

\section{Self-Evaluation}

\begin{tabular}{lllllll}
\hline No. & Questions & Strongly disagree & Disagree & Unsure & Agree & Strongly agree \\
\hline 1 & $\begin{array}{l}\text { You're very interested in English oral } \\
\text { expression. }\end{array}$ & $12.33 \%$ & $4.11 \%$ & $24.66 \%$ & $24.66 \%$ & $34.25 \%$ \\
2 & $\begin{array}{l}\text { You think English oral expression is really } \\
\text { important. }\end{array}$ & $5.48 \%$ & $1.37 \%$ & $19.18 \%$ & $21.92 \%$ & $52.05 \%$ \\
\hline
\end{tabular}

Table 2

Self-Evaluation

\begin{tabular}{llll}
\hline No. & Questions & Options & Proportion \\
\hline \multirow{2}{*}{3} & Which aspect do you think English oral expression is important & Study & $73.97 \%$ \\
& to you?[MOACA] & Life & $68.49 \%$ \\
& & Work & $79.45 \%$ \\
& & Improve a lot & $20.55 \%$ \\
4 & What's the change of your English oral expression ability in & Improve a little & $42.47 \%$ \\
& college? & No change & $16.44 \%$ \\
& & Descend a little & $9.59 \%$ \\
\hline
\end{tabular}

Note. MOACA: Mark out all correct answers.

According to Table 1, 52.05\% of participants strongly agreed that English oral expression was really important, but only 34.25\% strongly agreed that they were interested in English oral expression, reflecting the 
fact that "interest is always the best teacher". From this, it can be also inferred that the reason for college students' lack of English oral expression ability may be that they also lack interest. In Q4, most of them (42.47\%) chose "improve a little", which could be considered as normal. However, there were still nearly $40 \%$ of them who believed that their English oral expression ability in college hadn’t been improved, which can not be ignored.

Three kinds of reactions. When others are communicating with you in English, you may have different reactions depending on how good your English oral expression ability is. They are divided into three different stages in progressive relationship: no thoughts, no good expressions, and no clear or exact expressions. Questions about these three kinds of reactions are designed as follows, shown in Table 3.

Table 3

Three Kinds of Reactions

\begin{tabular}{|c|c|c|c|c|c|c|}
\hline No. & Questions & Strongly disagree & Disagree & Unsure & Agree & Strongly agree \\
\hline 5 & $\begin{array}{l}\text { You don't always have } \\
\text { thoughts when others } \\
\text { communicate with you in } \\
\text { English. }\end{array}$ & $19.18 \%$ & $24.66 \%$ & $35.62 \%$ & $8.22 \%$ & $12.33 \%$ \\
\hline 6 & $\begin{array}{l}\text { You don't always have no idea } \\
\text { of how to express you thoughts } \\
\text { well when others communicate } \\
\text { with you in English. }\end{array}$ & $12.33 \%$ & $19.18 \%$ & $35.62 \%$ & $19.18 \%$ & $13.7 \%$ \\
\hline 7 & $\begin{array}{l}\text { You fail to always express } \\
\text { yourself clearly and exactly } \\
\text { when others communicate with } \\
\text { you in English. }\end{array}$ & $8.22 \%$ & $19.18 \%$ & $31.51 \%$ & $24.66 \%$ & $16.44 \%$ \\
\hline
\end{tabular}

According to Table 3, over 20\% were at the first stage, over 30\% were at the second and over $40 \%$ were at the third, which shows that a certain number of college students fail to master English oral expression well. This data suggests that college students are aware that their English oral expression ability is limited and they need to improve it in different degrees. Actually, those three stages are a natural process of forming English oral expression ability; clearly realizing where you are can help you know the next goal and direction.

\section{Possible Factors}

Questions 8 to 21 in this questionnaire examined various reasons for the deficiency of college students' English oral expression ability. These questions are divided into three parts: individual factors, teaching factors and environmental factors.

Individual factor. Generally speaking, regardless of English oral expression ability or any other significant skills, individual is always the priority because only a person himself is the master of his own learning. The individual factor can be divided into three parts: mother tongue barrier, personal limited competence barrier and language anxiety barrier.

Mother tongue barrier. Schavan (2003) suggested that mother tongue may be the biggest barrier for youngsters on their way to learning language. Questions about mother tongue are designed as follows, shown in Table 4. 
Table 4

Mother Tongue Barrier

\begin{tabular}{llccccc}
\hline No. & Questions & Strongly disagree & Disagree & Unsure & Agree & Strongly agree \\
\hline 8 & $\begin{array}{l}\text { You may use Chinese English when } \\
\text { communicating with others. }\end{array}$ & $16.44 \%$ & $19.18 \%$ & $42.47 \%$ & $12.33 \%$ & $9.59 \%$ \\
$\begin{array}{l}\text { You think your mother tongue } \\
\text { (Chinese) has a tremendous influence } \\
\text { on English oral expression. }\end{array}$ & $12.33 \%$ & $17.81 \%$ & $42.47 \%$ & $17.81 \%$ & $9.59 \%$ \\
$\begin{array}{l}\text { You may think about well what you } \\
\text { want to say in Chinese first and then } \\
\text { translate it into English. }\end{array}$ & $16.44 \%$ & $13.7 \%$ & $24.66 \%$ & $30.14 \%$ & $15.07 \%$ \\
$\begin{array}{l}\text { You would like to express your idea in } \\
\text { English. }\end{array}$ & $20.55 \%$ & $17.81 \%$ & $38.36 \%$ & $15.07 \%$ & $8.22 \%$ \\
\hline
\end{tabular}

Over $60 \%$ of participants chose "Unsure, Agree and Strongly agree" for the first three questions and over $70 \%$ chose "Strong disagree, Disagree and Unsure" for the last one, which means most college students are going through mother tongue barriers to some extent.

Both Chinese traditional culture and Chinese customary expressive ways are possible explanations for the strength of the mother tongue barrier. Language is the supporter of the culture. If one doesn't know the culture, tradition or custom of a country, he can not really master its language. However, it is often hard for Chinese college students to make full sense of language because they are lacking of the knowledge of western cultural background and sensibility of cultural differences.

Limited personal competence barrier. It's still hard for college students to strengthen their English oral expression ability if their listening ability is poor or they aren't capable of pronouncing words well. Thus, limited personal competence is a barrier to oral expression ability. Questions about limited personal competence barrier are designed as follows, shown in Table 5.

Table 5

Limited Personal Competence Barrier

\begin{tabular}{llll}
\hline No. & Questions & Options & Proportion \\
\hline & & Incorrect pronunciation and & $42.47 \%$ \\
& & intonation. & $86.3 \%$ \\
12 & What causes do you think are the restriction on your & Insufficient basic knowledge. & Cross-cultural communication \\
& English oral expression ability? [MOACA] & ability. & $57.53 \%$ \\
& & Listening ability. & $49.32 \%$ \\
& & Shyness, inferiority, timidity. & $43.84 \%$ \\
\hline
\end{tabular}

Most students (86.3\%) couldn't express themselves well in English because some words, phrases, or sentences are new to them. Rank only second to insufficient basic knowledge, cross-cultural communication ability is also viewed as the main cause, which $57.53 \%$ took it as the restriction on their English oral expression ability. About half (49.32\%) of participants identified "Listening ability" as restricting their oral expression ability. For quite a number of them (42.47\%), even if their basic knowledge is not bad, appropriate pronunciation and intonation still takes their energy. Furthermore, a kind of mental factor, shyness, inferiority and timidity included, may restrict their development of English oral expression ability, as well. At last, 4.11\% students pointed out that they didn’t have enough opportunities to practice, which can't be ignored, as well. In this case, it represents that college students are lacking of English listening practice. Since listening always 
comes before speaking, students must be able to understand others before expressing themselves thoroughly and correctly. Therefore, limited listening ability leads to limited ability for oral expression.

Language anxiety barrier. According to Cheng (2007), language anxiety is the psychological state of being anxious and afraid to make mistakes during the process of language learning often experienced by language learners. Questions about language anxiety barrier are designed as follows, shown in Table 6.

Table 6

Language Anxiety Barrier

\begin{tabular}{llll}
\hline No. $\quad$ Questions & Options & Proportion \\
\hline & & Be afraid to make mistakes. & $17.81 \%$ \\
& & Don't want to seek the limelight and be afraid to & $21.92 \%$ \\
& \multirow{3}{*}{ Why are you afraid to speak in English? } & be misunderstood. & $53.42 \%$ \\
& Not excellent enough. & $2.74 \%$ \\
& English oral expression is not important. & $4.11 \%$ \\
\hline
\end{tabular}

Language anxiety affects the improvement of college students’ English oral expression ability. Many participants (43.84\%) selected "shyness, inferiority and timidity" as reasons they were afraid to speak in English. Over half (53.42\%) of them thought they weren't excellent enough, which shows the lack of confidence to a great extent. Moreover, $21.92 \%$ of participants did not want to seek the limelight and chose to keep silent for fear of being misunderstood. Since this group of students could include students of varying levels of English oral expression ability, it's possible that college students whose English oral expression is pretty good may choose not to speak. It could be considered as another restriction on improving English oral expression ability.

Teaching factor. Due to exam-oriented education, teachers and students pay much attention to problem-solving skills and blindly accentuate language knowledge input, often neglecting oral expression ability. Questions about teaching factors are shown in Table 7.

Table 7

Teaching Factor

\begin{tabular}{|c|c|c|c|}
\hline No. & Questions & Options & Proportion \\
\hline \multirow{3}{*}{14} & \multirow{3}{*}{$\begin{array}{l}\text { Does your English teacher organize English oral } \\
\text { expression practice or activities in class? }\end{array}$} & Yes, always. & $36.99 \%$ \\
\hline & & Yes, sometimes. & $46.58 \%$ \\
\hline & & No, never. & $16.44 \%$ \\
\hline \multirow{4}{*}{15} & \multirow{4}{*}{$\begin{array}{l}\text { How are most of your oral English teachers' oral } \\
\text { expression standards? }\end{array}$} & $\begin{array}{l}\text { Very good, pronunciation, intonation } \\
\text { and oral expression are all amazing. }\end{array}$ & $32.88 \%$ \\
\hline & & $\begin{array}{l}\text { So so, pronunciation, intonation and oral } \\
\text { expression are acceptable. }\end{array}$ & $58.9 \%$ \\
\hline & & $\begin{array}{l}\text { Hard to accept, accent is unacceptable, } \\
\text { pronunciation and intonation are bad. }\end{array}$ & $8.22 \%$ \\
\hline & & It doesn’t matter. & $0 \%$ \\
\hline \multirow{7}{*}{16} & \multirow{7}{*}{$\begin{array}{l}\text { Your English teacher helps to improve students' oral } \\
\text { expression ability in class by means of ... [MOACA] }\end{array}$} & Presentation. & $75.34 \%$ \\
\hline & & Interpretation. & $35.62 \%$ \\
\hline & & Group discussion. & $61.64 \%$ \\
\hline & & Personal comments. & $32.88 \%$ \\
\hline & & Role play. & $42.47 \%$ \\
\hline & & Game. & $32.88 \%$ \\
\hline & & Else. & $4.11 \%$ \\
\hline
\end{tabular}


(Table 7 continued)

\begin{tabular}{llll}
\hline No. & Questions & Options & Proportion \\
\hline \multirow{4}{*}{17} & \multirow{4}{*}{ What's your general reaction to above activities? } & Enthusiastic participation. & $26.03 \%$ \\
& & Forced to accept it, but can cooperate & $34.25 \%$ \\
& with teachers. & Take part in but not willing to give & $24.66 \%$ \\
& & opinions. & $15.07 \%$ \\
18 & The do you think plays the most significant role in & Individual. & $52.7 \%$ \\
& Whancing your English oral expression ability? & Teacher. & $9.46 \%$ \\
\hline
\end{tabular}

According to Table 7, it shows that most of oral English teachers' expression standards need to be improved because there were only 32.88\% students who gave high evaluation to their teachers. Based on Q14, Q16 and Q17, it shows that even though some teachers actually did take their responsibility, trying their best to organize English oral expression activities in class to impress students, over $70 \%$ took negative attitudes on them, such as being forced and not willing to do so. Above all, teachers' oral expression ability should be improved and their methods of teaching also need to innovate and reform.

Environmental factor. Language environment is critical for second language learning. Real language environment can ignite students' desire for learning English oral expression and inspire them to be more confident. Questions about environmental factors are shown in Table 8 and Table 9.

Table 8

Environmental Factor

\begin{tabular}{|c|c|c|c|c|c|c|}
\hline No. & Questions & Strongly disagree & Disagree & Unsure & Agree & Strongly agree \\
\hline 19 & $\begin{array}{l}\text { You think that language environment is really } \\
\text { helpful for improving English. }\end{array}$ & $10.96 \%$ & $1.37 \%$ & $12.33 \%$ & $17.81 \%$ & $57.53 \%$ \\
\hline 20 & $\begin{array}{l}\text { You have plenty of opportunities to } \\
\text { communicate with others in English in your } \\
\text { daily life. }\end{array}$ & $28.77 \%$ & $35.62 \%$ & $17.81 \%$ & $10.96 \%$ & $6.85 \%$ \\
\hline
\end{tabular}

More than half of participants (57.53\%) strongly agreed that language environment is really helpful for improving English. However, only 6.85\% of participants gave affirmative answers on having enough opportunities to practice oral English.

Table 9

Environmental Factor

\begin{tabular}{llll}
\hline No. & Questions & Options & Proportion \\
\hline & & In English class. & $90.41 \%$ \\
& & Extracurricular activities/ & $54.79 \%$ \\
& & Oral English training. & \\
& Under what kind of circumstances are those above & Communication with net & $21.92 \%$ \\
& opportunities given? [MOACA] & friends. & $27.4 \%$ \\
& & Friends and classmates & around. \\
& & Else. & $2.74 \%$ \\
\hline
\end{tabular}

What's more, according to Table 9, the most of participants (90.41\%) admitted that opportunities are given in class, which in some way proves that they don't have enough chance or language environment to practice 
and improve their English oral expression ability.

\section{Strategies to Overcome English Oral Expression Ability Barriers}

\section{To Overcome Individual Factor}

To acquaint language cultural background. Due to different language cultural background, while English learners are communicating with native speakers, their English oral expressions are not as expected as they do in most cases. Cultural factor exists in the simplest communicative activities. Thus, teachers should arrange more time to teach students cultures from English speaking countries.

A full-English environment is also necessary to let college students leave the mother tongue environment and reduce the use of Chinese English, which may be the most helpful strategy for overcoming Chinese customary expressive ways.

To overcome limited personal competence barrier. The first step to stride on the way to enhancing English oral expression ability is to lay a firm foundation of pronunciation and intonation. Students should clearly know the differences between American English and British English. They can practice the two different accents through VOA or BBC in order to get standard pronunciation, including standard intonation, pitch, stress and rhythm.

The next step is to accumulate words. Tremendous restoration of vocabulary is the base of oral expression. It is the most helpful because a sentence consists of words.

The premise of one's successful communication is to understand what the other says and respond appropriately. Language acquisition always starts from listening. College students should practice listening skill a lot in daily study. The more they listen, the more information they can get to express their ideas with others.

To overcome language anxiety. This study shows that language anxiety influences English oral expression much. The more anxious students are, the worse their oral expression is. In order to address this anxiety, college English teachers could use the communicative teaching method and set more real language environment to organize activities to improve students' oral ability. As for students themselves, when communicating with others in English, they should focus on the content of communication, but not grammar or word sequence. The key point of oral expression is to let others understand what you say, not the beauty of your ways to communicate.

\section{To Overcome Teaching Factor}

In order to cultivate students' English oral expression ability, the class should be set in a real language situation and teachers can use modern teaching methods to make teaching atmosphere active. In this way, not only the teaching quality can be improved, but also students' passion can be inspired to learn English for fun.

\section{To Overcome Environmental Factor}

One of the most important factors to affect college students' oral expression ability is lacking opportunities to communicate with native speakers. Creating an authentic and full English language environment is another task for universities and colleges to address this barrier, such as English corner and full English communication atmosphere in campus.

\section{Conclusion}

This paper carried out a questionnaire survey on 146 college students from different majors, grades, 
universities and areas to study their English oral expression barriers. The major findings of this study can be summarized as follows. First, this paper describes the current status of college-student oral expression ability, including three kinds of reactions: no thoughts, no good expressions and no clear or exact expressions. Second, there are three main factors affecting English oral expression ability: individual, teaching, and environmental. Individual factors include mother tongue barrier, limited personal competence barrier and language anxiety barrier. Teaching factors include insufficient teaching ability and customary teaching methods. Meanwhile, environmental factors are equally significant, too. Among them, individual factors are the most important of three because 52.7\% voted for individual effect in Q18.

What's more, this paper suggests some possible solutions to overcome English expression ability barriers against individual factors, teaching factors and environmental factors. They are to learn more cultural background of English speaking countries, to practice pronunciation, to focus more on improving English skill, to overcome personal anxiety in learning English, and to set more real language atmosphere to arouse students' interests to learn English for fun, etc.

\section{References}

CHENG, Y. P. (2007). The influence on English classroom anxiety on college-student English oral expression. Language Teaching and Study, (1), 89-89.

GUO, Y. L. (2004). The study on college-student English oral expression ability training. Dalian University Journal, 25(1), 105-107.

WANG, J. M. (2014). Reflections on college-student English Oral expression ability training. Education Exploration, (7), 48.

ZHANG, C. Z., \& HUANG, L. (2011). The discussion on strategies of enhancing college-student English oral expression ability. Overseas English, (2), 38.

ZHAO, Z. J. (2013). Strategies for contemporary college-student English oral expression ability. Theoretical Frontiers, (12), $141-142$.

ZHENG, C. G. (2010). The discussion on enhancing college-student English oral expression ability. Jilin Provincial Institute of Education Journal, (5), 89.

ZHU, H. (2011). Strategies for improving English oral expression ability. Jilin Radio and TV University Journal, (12), $133-134$. 